
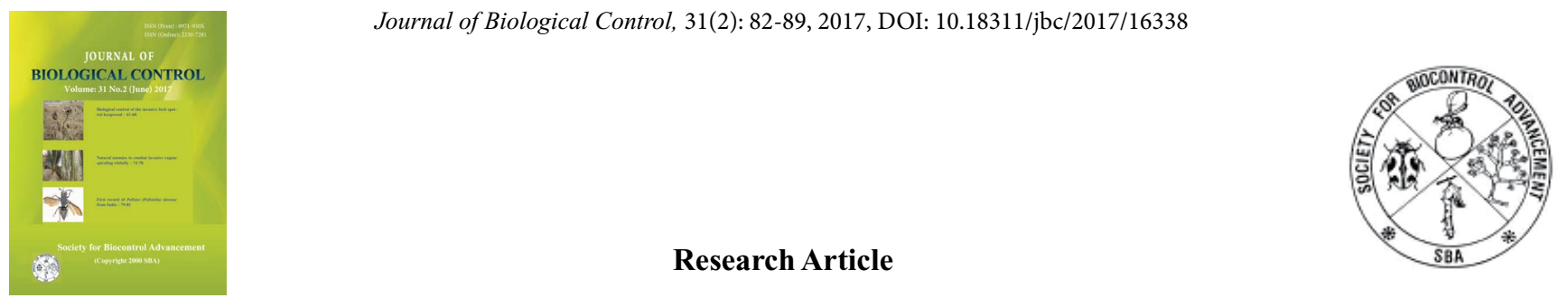

\title{
Temperature based differences in biological parameters of some potential species/strains of Trichogramma
}

\author{
ENAKSHI GHOSH ${ }^{*}$, CHANDISH R. BALLAL ${ }^{1}$ and ABRAHAM VERGHESE ${ }^{2}$ \\ Department of Biotechnology, Center for Post Graduate Studies, Jain University, Jayanagar, 9 Bengaluru - 560011, Karnataka, India \\ ${ }^{1}$ ICAR-National Bureau of Agricultural Insect Resources, P. Bag No. 2491, H.A Farm post, Bellary Road, Bangalore - 24, India \\ ${ }^{2}$ GPS Institute of Agricultural Management, Bengaluru - 560058, India \\ ${ }^{*}$ Corresponding author E-mail: enakshi.ghosh1@gmail.com
}

\begin{abstract}
The effect of temperature on different Trichogramma spp. is an aspect to be understood for planning mass production strategies and further field releases. The key biological parameters of seven different spp./strains of trichogrammatids (viz. Trichogramma japonicum Ashmead, T. cordubensis Vargas and Carbello, T. achaeae Nagaraja and Nagarkatti, four strains of T. chilonis Ishii i.e. lab strain, Nilgiris strain, Kodaikanal strain and a strain acclimatized to constant $\left.15^{\circ} \mathrm{C}\right)$ were investigated at five constant temperatures $(16,21,26,31$ and $36 \pm 1{ }^{\circ} \mathrm{C}$ with $60-70 \% \mathrm{RH}$ and L: D-12:12). The different test temperatures had a significant impact on the biological parameters of the different species/strains. Based on longevity, parasitism and fecundity attributes, the best temperature to propagate these trichogrammatids was found to be $26^{\circ} \mathrm{C}$. Considering the higher parasitism rates and the ability to parasitize and remain fecund at varied temperatures, $T$. chilonis Nilgiris strain proved to be the best. From the linear model of regression analysis, the upper temperature thresholds ranged from 35 to $46.37^{\circ} \mathrm{C}$ and the lower temperature thresholds were recorded to range between 9 and $12^{\circ} \mathrm{C}$, with $T$. cordubensis appearing to be least temperature sensitive.
\end{abstract}

KEY WORDS: Biology, effect of temperature, Trichogramma

(Article chronicle: Received: 22.03.2017; Revised: 26.05.2017; Accepted: 10.06.2017

\section{INTRODUCTION}

Trichogrammatids are utilized as potential bio-control agents in integrated management of lepidopteran pests of various crops (Chailleux et al., 2013; Corrigan and Laing, 1994; El-Arnaouty et al., 2014). Their ability to provide $100 \%$ parasitism in favourable conditions and their amenability to rearing have made them one of the most widely used bio-control agents. Inundative releases of Trichogramma species have proved to be effective against several pests, especially where the natural enemy development is not disrupted by chemical pesticides (Briere et al., 1999; Garcia et al., 1995b). When released in the field, these parasitoids experience fluctuating abiotic conditions including temperature variations, which play a major role in determining their rate of development and survival (Foester and Foester, 2009; Pizzol et al., 2010; Ratte, 1985). Different fitness attributes change based on how temperature communicates with different species/strains of natural enemies and also the host (Pizzol et al., 2010; Reznik and Vaghina, 2006). In Asiatic countries, Corcyra cephalonica (Stainton) (Lepidoptera: Pyralidae) is preferred as a factitious host as it can be reared by adopting a simple and easy production protocol.
The relationship between constant temperatures and development of insects is generally linear within the threshold limit of temperatures. It is important to identify the temperature range within which an insect parasitoid remains active as it can influence the outcome of its field release. Selection of the optimum temperature for rearing helps in standardization of production protocols for mass rearing of quality parasitoids leading to successful biological control. In India at least 28 species of Trichogrammatids are known to occur, out of which Trichogramma chilonis (Ishii) and $T$. japonicum (Ashmead) are highly efficient egg parasitoids that are used extensively for pest management in tomato, sugarcane, cotton and rice ecosystems, while Trichogramma achaeae Nagaraja and Nagarkatti has shown promising results against Acanthodelta (=Achaeae) janata (Linn.) (Noctuidae) on castor (Lalitha and Ballal, 2015; Lingappa and Hegde, 2001; Nagarkatti and Nagaraja, 1977; Singh et al., 2001). Trichogramma cordubensis Vargas and Carbellois an exotic species, which is used world-wide to target Autographa gamma (L.), Chrysodeixis chalcites (Esper), Phlogophora meticulosa (L.), Peridroma saucia (Hübner), Xestia c-nigrum (L.) and Noctua pronuba (L.) (Garcia et al., 1995b; Garcia et al., 1995). In India, T. chilonis is rec- 
ognised as the most promising indigenous species, which has a wider host range and high survival capacity. Hence, in the current study four strains of $T$. chilonis along with three other important species (T. cordubensis, T. japonicum, $T$. achaeae) were chosen to compare their responses to temperature variations and their fitness attributes which would enable us to select the best strain for future research on short and long term storage. The aim was also to study their thermal requirements, to identify the most suitable rearing temperature for each of the species/strains and to identify the superior spp./strain which is amenable to rearing. The performances of continuously lab reared populations at different rearing temperatures differed from those of field collected populations, which had undergone only few generations in the laboratory.

\section{MATERIALS AND METHODS}

\section{Maintenance of Trichogramma spp}

Pure cultures of T. japonicum (National Accession No: NBAII-MP-Tr-65), T. achaeae (NBAII-MP-Tr-06),T. cordubensis (NBAII-MP-Tr-55) and four strains of T. chilonis viz. two high altitude strains, collected from Nilgiris (NBAII-MP-Tr-23a) and Kodaikanal (NBAII-MP-Tr-23b), lab strain (NBAII-MP-Tr-13) and a low temperature tolerant strain / reared at $15^{\circ} \mathrm{C}$ (NBAII-MP-Tr-25) are being reared continuously in the insectary of ICAR-NBAIR, Bangalore. An alternative laboratory host Corcyra cephalonica Stainton (Lepidoptera: Pyralidae) is used for rearing Trichogramma spp. Rearing of C. cephalonica was done by following protocol suggested by Lalitha and Ballal (2015). UV irradiated ( $30 \mathrm{~W}$ UV tube for 45 minutes at a distance of 2 feet) Corcyra eggs were glued on 'Tricho' cards ( $15 \mathrm{x}$ $10 \mathrm{~cm})$. These eggs are exposed to adult females of Trichogramma spp./strains in the ratio of 40:1 until mortality. For experimental purposes, cultures of each species/ strains were maintained in tubes at $25 \pm 1^{\circ} \mathrm{C}$ with $14 \mathrm{~h}$ light and $65 \pm 10 \% \mathrm{RH}$.

\section{Evaluation of biological parameters of Trichogramma spp. at different temperatures}

Twenty five sets of hundred UV irradiated eggs of Corcyra cephalonica (for each spp./strain) were pasted on thick card pieces $(2 \times 1 \mathrm{~cm})$ and exposed to T. chilonis (all four strains), T. achaeae, T. cordubensis and T. japonicum adults separately in tubes $(14 \times 2.5 \mathrm{~cm})$ in the ration of $1: 40$ (adult females: host eggs)at room temperature and the tubes plugged with cotton wool. After 24 hours, the parasitized egg cards were used for the experiment. The experiment was conducted in a temperature gradient chamber (NK system-TG-180 CCFL-5LE model) set at the test temperatures, viz., 16, 21, 26, 31, 36 $\pm 1^{\circ} \mathrm{C}$ (with $\mathrm{L}: \mathrm{D}=12$ : 12 , $\mathrm{RH}=60 \pm 10 \%$ ). Parasitized cards were placed in glass vials (with tight cotton plug) and kept on racks and each rack set at the constant test temperature (as indicated above). Five replications were maintained for each spp./strain at each temperature treatment. Once the adults started emerging, $10 \%$ honey solution was provided. Data was recorded on number of adults emerged, number of days from the date of parasitism to adult emergence (recorded as developmental duration) and longevity of the adults (male and female).

To check percent parasitism and fecundity an additional experiment was set up. Two mated females emerging from each of the treatments were transferred into separate vials with $10 \%$ honey solution (as streaks on the wall of the tube) as their diet. In a 1: 30 parasitoid host egg ratio, exposures were made for 24 hours in each tube and this was performed in five different replications and repeated every $24 \mathrm{~h}$ throughout the effective parasitizing period (first three days after emergence). This was repeated for each spp./strain at the five test temperatures. From these exposed cards, percent parasitism was calculated based on the average of number of blackened eggs over the total number eggs provided each day. The average number of progeny produced per day by each female was calculated as mean daily fecundity while the total progeny produced by each female in their whole fecund life time was considered as mean life time fecundity.

These data were subjected to one way analysis of variance (ANOVA) a) with different temperature regimes as the main effects (factors) and the biological parameters (viz. development duration, longevity, mean daily fecundity, mean life-time fecundity and mean percent parasitism) as response variables b) set temperature, spp./strains were selected as main effect and biological parameters were selected as response variable followed by least significance difference test at 0.05 level of probability by using SPSS 16.0. When there large variations were observed between the different treatment values, the mean percentage values $(\mathrm{X}+0.5)$ were subjected to angular transformation and whole numbers to square root transformation $(\sqrt{\mathrm{X}+0.5})$ in order to normalize the data.

\section{Calculating threshold temperatures}

The developmental rates of the different spp./strains as the dependent variables were used for regression analysis with temperature as the independent variable. Estimates of the respective lower development thresholds was calculated by the ' $x$ ' intercept method by setting regression equation to zero development per day(Arnold, 1959). Thermal constant $(\mathrm{K})$, expressed in degree-days (DD), is the amount of heat units that each species requires to complete its lifecycle or part of it above and below the threshold temperature, 
regardless of the temperature to which it is exposed (Urra et al., 2005), mathematically being the reciprocal of the slope (b) of the regression line and was calculated as suggested by Morris and Fulton (Morris and Fulton, 1970). Linear degree day model was opted in this study as it has the advantage of simplicity and allows estimation of developmental threshold and the degree day requirements of the insect species (Briere et al., 1999).

\section{RESULTS AND DISCUSSION}

\section{Developmental duration}

The highest developmental duration for all the spp./ strains was recorded at $16^{\circ} \mathrm{C}$. With increasing temperature, there was a gradual decrease in developmental duration. The minimum developmental duration was recorded at $36^{\circ} \mathrm{C}$ for T. japonicum, T. achaeae and T. chilonis Kodaikanal, while for the other species/strains minimum developmental duration was recorded at both 31 and $36^{\circ} \mathrm{C}$. Significantly higher development duration was recorded for T. cordubensis at all set test temperatures (Table 1).

\section{Temperature thresholds}

The relationship between developmental duration and temperature for the test spp./strains is depicted in Table 3. The calculated lower threshold (LT) temperatures ranged between 9.3 to $12^{\circ} \mathrm{C}$ and the upper threshold temperature ranged between 35 to $46.37^{\circ} \mathrm{C}$ with the minimum LT and maximum UT recorded in the case of T. cordubensis, T. japonicum, $T$. achaeae, T. cordubensis, T. chilonis lab, T. chilonis Nilgiris, $T$. chilonis $15^{\circ} \mathrm{C}$ and T. chilonis Kodaikanal needed 166.66, 200, $333,166.66,166.66,142.85$ and $166.66 \mathrm{DD}$, respectively to complete their development (Table 3).

Table 1. Effect of constant set test temperatures on the development duration, longevity and Mean Percent parasitism of Trichogramma spp./strains (L:D- 12:12, RH- 60-70\%)

\begin{tabular}{|c|c|c|c|c|c|c|c|c|c|c|c|c|}
\hline $\begin{array}{l}\text { Biological } \\
\text { Parameters } \\
(\text { Mean } \pm \text { SE })\end{array}$ & $\begin{array}{l}\text { Tm } \\
\left( \pm 1^{\circ} \mathrm{C}\right)\end{array}$ & T. jap & T. ach & T. cor & T. ch lab & $\begin{array}{l}\text { T. } c h \\
\text { Nilgiris }\end{array}$ & $\begin{array}{l}\text { T.ch } \\
15^{\circ} \mathrm{C}\end{array}$ & $\begin{array}{l}\text { T. ch } \\
\text { Kodai }\end{array}$ & $\mathrm{df}$ & $\mathrm{F}$ & $\mathrm{P}$ & $\begin{array}{l}\text { LSD } \\
\text { at } \mathrm{P} \leq \\
0.05 \\
\end{array}$ \\
\hline \multirow{9}{*}{$\begin{array}{l}\text { Develop- } \\
\text { mental dura- } \\
\text { tion (days) }\end{array}$} & 16 & $25.2 \pm 0.2$ & $29.4 \pm 0.2$ & $30.6 \pm 0.2$ & $17.4 \pm 0.2$ & $30.8 \pm 0$ & $27.4 \pm 0.2$ & $29.8 \pm 0$ & 6,28 & 441.3 & $\leq 0.001$ & 0.7 \\
\hline & 21 & $14.2 \pm 0.2$ & $16.0 \pm 0$ & $18.8 \pm 0.2$ & $11.0 \pm 0$ & $16.8 \pm 0$ & $13.4 \pm 0.2$ & $15.8 \pm 0$ & 6,28 & 203.5 & $\leq 0.001$ & 0.5 \\
\hline & 26 & $9.2 \pm 0.2$ & $10.4 \pm 0$ & $10.4 \pm 0.2$ & $8.0 \pm 0$ & $10.0 \pm 0$ & $9.4 \pm 0.2$ & $8.8 \pm 0$ & 6,28 & 15.2 & $\leq 0.001$ & 0.7 \\
\hline & 31 & $7.2 \pm 0.2$ & $8.0 \pm 0$ & $8.4 \pm 0$ & $6.0 \pm 0$ & $7.0 \pm 0$ & $5.8 \pm 0.2$ & $7.4 \pm 0$ & 6,28 & 21.4 & $\leq 0.001$ & 0.6 \\
\hline & 36 & $6.0 \pm 0.2$ & $7.0 \pm 0$ & $8.2 \pm 0$ & $6.0 \pm 0$ & $6.5 \pm 0$ & $5.4 \pm 0.2$ & $6.6 \pm 0$ & 6,28 & 35.4 & $\leq 0.001$ & 0.4 \\
\hline & $\mathrm{df}$ & 4,20 & 4,20 & 4,20 & 4,20 & 4,20 & 4,20 & 4,20 & & & & \\
\hline & $\mathrm{F}$ & 673.9 & 3531 & 1771 & 1901 & 1835 & 1462 & 1976 & & & & \\
\hline & $\mathrm{P}$ & $\leq 0.001$ & $\leq 0.001$ & $\leq 0.001$ & $\leq 0.001$ & $\leq 0.001$ & $\leq 0.001$ & $\leq 0.001$ & & & & \\
\hline & $\begin{array}{l}\mathrm{LSD} \text { at } \\
\mathrm{P} \leq 0.05\end{array}$ & 0.5 & 0.46 & 0.67 & 0.32 & 0.7 & 0.7 & 0.65 & & & & \\
\hline \multirow{9}{*}{$\begin{array}{l}\text { Longevity } \\
\text { (days) }\end{array}$} & 16 & $6.6 \pm 0.2$ & $7.8 \pm 0.2$ & $9.6 \pm 0$ & $6.4 \pm 0.2$ & $6.0 \pm 0$ & $6.6 \pm 2.4$ & $7.0 \pm 0$ & 6,28 & 37.2 & $\leq 0.001$ & 0.6 \\
\hline & 21 & $5.0 \pm 0.2$ & $6.4 \pm 0.2$ & $7.8 \pm 0$ & $5.0 \pm 0$ & $9.0 \pm 0$ & $5.2 \pm 0.2$ & $6.0 \pm 0$ & 6,28 & 11.8 & $\leq 0.001$ & 0.4 \\
\hline & 26 & $4.6 \pm 0.2$ & $6.2 \pm 0.2$ & $7.8 \pm 0$ & $4.0 \pm 0$ & $8.6 \pm 0$ & $5.8 \pm 0.2$ & $6.0 \pm 0$ & 6,28 & 59.0 & $\leq 0.001$ & 0.5 \\
\hline & 31 & $3.6 \pm 0.2$ & $6.2 \pm 0.2$ & $3.4 \pm 0$ & $3.6 \pm 0.2$ & $4.0 \pm 0$ & $4.2 \pm 0.2$ & $3.4 \pm 0$ & 6,28 & 21.5 & $\leq 0.001$ & 0.6 \\
\hline & 36 & $3.0 \pm 0.2$ & $4.8 \pm 0.2$ & $3.0 \pm 0$ & $3.0 \pm 0.2$ & $4.0 \pm 0$ & $3.5 \pm 0.2$ & $3.0 \pm 0$ & 6,28 & 34.4 & $\leq 0.001$ & 0.3 \\
\hline & $\mathrm{df}$ & 4,20 & 4,20 & 4,20 & 4,20 & 4,20 & 4,20 & 4,20 & & & & \\
\hline & $\mathrm{F}$ & 53.55 & 25.72 & 183 & 74.1 & 484 & 28.9 & 261 & & & & \\
\hline & $\mathrm{P}$ & $\leq 0.001$ & $\leq 0.001$ & $\leq 0.001$ & $\leq 0.001$ & $\leq 0.001$ & $\leq 0.001$ & $\leq 0.001$ & & & & \\
\hline & $\begin{array}{l}\mathrm{LSD} \text { at } \\
\mathrm{P} \leq 0.05\end{array}$ & 0.56 & 0.62 & 0.18 & 0.45 & 0.32 & 0.64 & 0.32 & & & & \\
\hline \multirow{9}{*}{$\begin{array}{l}\text { Parasitism }{ }^{\#} \\
(\%)\end{array}$} & 16 & $53.0 \pm 0.2$ & 0 & $34.4 \pm 1.5$ & $37.3 \pm 3.2$ & $47.2 \pm 1.9$ & \begin{tabular}{|l|l}
$39.4 \pm 1.8$ \\
\end{tabular} & $44.0 \pm 3.5$ & 6,28 & 93.7 & $\leq 0.001$ & 4.3 \\
\hline & 21 & $46.2 \pm 0.9$ & $40.4 \pm 2.1$ & $51.1 \pm 2.6$ & $33.7 \pm 4.1$ & $50.6 \pm 1.5$ & $42.6 \pm 0.7$ & $50.8 \pm 2.7$ & 6,28 & 5.7 & $\leq 0.001$ & 4.6 \\
\hline & 26 & $52.2 \pm 0.9$ & $58.4 \pm 1.6$ & $56.4 \pm 3.4$ & $52.6 \pm 1.2$ & $53.6 \pm 2.3$ & $55.2 \pm 1.2$ & $48.2 \pm 3.3$ & 6,28 & 1.02 & $\leq 0.001$ & NS \\
\hline & 31 & $47.0 \pm 1.3$ & $64.8 \pm 1.4$ & $34.4 \pm 2.4$ & $35.5 \pm 1.6$ & $58.6 \pm 1.5$ & $54.4 \pm 1.7$ & $48.8 \pm 2.2$ & 6,28 & 16.5 & $\leq 0.001$ & 5.1 \\
\hline & 36 & $49.3 \pm 2.3$ & $50.2 \pm 3.7$ & 0 & $30.6 \pm 2.8$ & $64.6 \pm 3.7$ & $48.8 \pm 4.9$ & $44.4 \pm 2.5$ & 6,28 & 86.1 & $\leq 0.001$ & 5.0 \\
\hline & $\mathrm{df}$ & 4,20 & 4,20 & 4,20 & 4,20 & 4,20 & 4,20 & 4,20 & & & & \\
\hline & $\mathrm{F}$ & 53.55 & 25.72 & 183 & 74.1 & 484 & 28.9 & 261 & & & & \\
\hline & $\mathrm{P}$ & $=0.65$ & $\leq 0.001$ & $\leq 0.001$ & $\leq 0.001$ & $\leq 0.001$ & $\leq 0.001$ & $=0.4$ & & & & \\
\hline & $\begin{array}{l}\text { LSD at } \\
\mathrm{P} \leq 0.05\end{array}$ & NS & 4.62 & 0.18 & 0.45 & 0.32 & 0.64 & NS & & & & \\
\hline
\end{tabular}

T. jap- T. japonicum, T. ach- T. achaeae, T. cor- T. cordubensis, T. ch lab - T. chilonis Laboratory strain, T. ch Nigiris- T. chilonis Nilgiris strain, T. ch $15^{\circ} \mathrm{C}$ - T. chilonis maintained at $15^{\circ} \mathrm{C}$, T. ch Kodai- T. chilonis Kodaikanal strain \# Analysis based on angular transformed values, Formula used: average number of blackened eggs/total eggs provided X 100 


\section{Longevity}

The highest longevity was recorded at $16^{\circ} \mathrm{C}$ for all the spp./strains except $T$. chilonis Nilgiris where significantly higher longevity of 9 days was recorded at $21^{\circ} \mathrm{C}$. The lowest recorded longevity was at $36^{\circ} \mathrm{C}$ for all the spp./strains except $T$. chilonis Nilgiris and T. chilonis $15^{\circ} \mathrm{C}$ which recorded equally short longevity at 31 and $36^{\circ} \mathrm{C}$. When the longevity of different spp./strains were compared at each test temperature, $T$. cordubensis emerged as significantly superior at $16^{\circ} \mathrm{C}, T$. chilonis Nilgiris at 21 and $26^{\circ} \mathrm{C}$ and $T$. achaeae at 31 and $36^{\circ} \mathrm{C}$ ( Table 1).

\section{Mean percentage parasitism (M\%P)}

Temperature had no significant effect on mean percent parasitism of $T$. japonicum and T. chilonis Kodaikanal atrain. In case of $T$. achaeae the highest parasitism was recorded at 26 and $31^{\circ} \mathrm{C}$, for T. cordubensis at 21 and $26^{\circ} \mathrm{C}$, for T. chilonis lab population at $26^{\circ} \mathrm{C}$, for T. chilonis Nilgiris 31 and $36^{\circ} \mathrm{C}$ and for T. chilonis $15^{\circ} \mathrm{C}$ from 26 to $36^{\circ} \mathrm{C}$. When compared across the different spp./strains T. chilonis Nilgiris recorded higher parasitism at the test temperatures. However, parasitism rates of T. japonicum at $16^{\circ} \mathrm{C}, T$. cordubensis and T. chilonis Kodaikanal at $31^{\circ} \mathrm{C}$ and T. achaeae at $31^{\circ} \mathrm{Cwere}$ statistically similar to those of $T$. chilonis Nilgiris at the same temperatures (Table 1).

\section{Mean daily fecundity (MDF)}

Temperature had no significant effect on MDF of $T$. japonicum, T. chilonis Nilgiris and T. chilonis Kodaikanal. Highest MDF for T. achaeae was recorded at $31^{\circ} \mathrm{C}$, for $T$. chilonis lab at $26^{\circ} \mathrm{C}$. T. chilonis $15^{\circ} \mathrm{C}$ and T. cordubensis showed equally good MDF at $26,31^{\circ} \mathrm{C}$ and $21,26^{\circ} \mathrm{C}$, respectively. While comparing different spp./strains, T. chilonis Nilgiris recorded high MDF at all the test temperatures,

Table 2. Effect of constant set test temperatures on the mean daily fecundity, mean life-time fecundity and percent emergence of Trichogramma spp./strains (L:D- 12:12, RH- 60-70\%)

\begin{tabular}{|c|c|c|c|c|c|c|c|c|c|c|c|c|}
\hline $\begin{array}{l}\text { Biological } \\
\text { Parameters } \\
(\text { Mean } \pm \text { SE })\end{array}$ & $\begin{array}{l}\mathrm{Tm} \\
\left( \pm 1^{\circ} \mathrm{C}\right)\end{array}$ & T. jap & T. ach & T. cor & T. ch lab & $\begin{array}{l}\text { T. ch } \\
\text { Nilgiris }\end{array}$ & $\begin{array}{l}\text { T. ch } \\
15^{\circ} \mathrm{C}\end{array}$ & $\begin{array}{l}\text { T. ch } \\
\text { Kodai }\end{array}$ & df & $\mathrm{F}$ & $\mathrm{P}$ & $\begin{array}{l}\text { LSD } \\
\text { at } \mathrm{P} \leq \\
0.05\end{array}$ \\
\hline \multirow{9}{*}{$\begin{array}{l}\text { Daily Fecun- } \\
\text { dity (Aver- } \\
\text { age progeny/ } \\
\text { day) } 0.28\end{array}$} & 16 & $12.1 \pm 1.7$ & 0 & $8.3 \pm 0.3$ & $10.3 \pm 1.1$ & $13.1 \pm 0.6$ & $7.3 \pm 0.6$ & $12.0 \pm 0.9$ & 6,28 & 102.5 & $\leq 0.001$ & 0.28 \\
\hline & 21 & $12.3 \pm 1.2$ & $10.2 \pm 1.3$ & $12.1 \pm 0.8$ & $8.1 \pm 1.1$ & $14.5 \pm 1.1$ & $8.4 \pm 0.6$ & $13.4 \pm 1.7$ & 6,28 & 203.5 & $\leq 0.001$ & 0.4 \\
\hline & 26 & $13.5 \pm 1.2$ & $6.2 \pm 0.4$ & $13.1 \pm 0.8$ & $14.5 \pm 0.9$ & $15.9 \pm 1.3$ & $13.8 \pm 0.5$ & $11.8 \pm 1.1$ & 6,28 & 15.2 & $\leq 0.001$ & 0.3 \\
\hline & 31 & $12.6 \pm 0.2$ & $18.3 \pm 0.8$ & $7.7 \pm 0.5$ & $7.3 \pm 0.3$ & $13.0 \pm 0.9$ & $13.7 \pm 0.4$ & $11.2 \pm 1.1$ & 6,28 & 21.4 & $\leq 0.001$ & \\
\hline & 36 & $11.8 \pm 1.3$ & $12.7 \pm 0.8$ & 0 & $7.7 \pm 1.02$ & $14.0 \pm 0.6$ & $11.7 \pm 0.5$ & $9.8 \pm 0.6$ & 6,28 & 35.4 & $\leq 0.001$ & 0.4 \\
\hline & df & 4,20 & 4,20 & 4,20 & 4,20 & 4,20 & 4,20 & 4,20 & & & & \\
\hline & $\mathrm{F}$ & 0.268 & 145 & 166.4 & 10.94 & 1.54 & 33.35 & 2.6 & & & & \\
\hline & $\mathrm{P}$ & $=0.8$ & $\leq 0.001$ & $\leq 0.001$ & $\leq 0.001$ & $=0.2$ & $\leq 0.001$ & $=0.1$ & & & & \\
\hline & $\begin{array}{l}\text { LSD at } \\
\mathrm{P} \leq 0.05\end{array}$ & NS & 0.3 & 0.3 & 2.7 & NS & 1.5 & NS & & & & \\
\hline \multirow{9}{*}{$\begin{array}{l}\text { Life-time fe- } \\
\text { cundity (To- } \\
\text { tal progeny/ } \\
\text { female's } \\
\text { lifetime }\end{array}$} & 16 & $24.2 \pm 3.3$ & 0 & $41.6 \pm 1.7$ & $30.8 \pm 1.1$ & $65.7 \pm 2.9$ & $36.6 \pm 3.1$ & $46.8 \pm 3.8$ & 6,28 & 138.9 & $\leq 0.001$ & 0.6 \\
\hline & 21 & $37.0 \pm 2.5$ & $30.6 \pm 3.4$ & $36.2 \pm 2.3$ & $24.0 \pm 3.2$ & $72.6 \pm 5.8$ & $42.2 \pm 3$ & $53.0 \pm 3.4$ & 6,28 & 19.52 & $\leq 0.001$ & 0.8 \\
\hline & 26 & $40.6 \pm 2.5$ & $43.8 \pm 3.4$ & $39.2 \pm 2.5$ & $43.2 \pm 2$ & \begin{tabular}{|l|}
$79.4 \pm 0.6$ \\
\end{tabular} & $55.2 \pm 1.9$ & $47.4 \pm 3.8$ & 6,28 & 12.81 & $\leq 0.001$ & 0.7 \\
\hline & 31 & $25.2 \pm 2.6$ & $54.4 \pm 2.5$ & $23.2 \pm 1.6$ & $21.8 \pm 0.8$ & $64.8 \pm 4.6$ & $54.8 \pm 1.6$ & $33.4 \pm 2$ & 6,28 & 56.00 & $\leq 0.001$ & 0.5 \\
\hline & 36 & $23.6 \pm 2.3$ & $25.4 \pm 1.5$ & 0 & $22.8 \pm 4.1$ & $69.0 \pm 2.8$ & $46.8 \pm 1.8$ & $29.8 \pm 1.5$ & 6,28 & 87.04 & $\leq 0.001$ & 0.7 \\
\hline & $\mathrm{df}$ & 4,20 & 4,20 & 4,20 & 4,20 & 4,20 & 4,20 & 4,20 & & & & \\
\hline & $\mathrm{F}$ & 8.65 & 25.72 & 0.5 & 7.7 & 1.54 & 11.4 & 10.5 & & & & \\
\hline & $\mathrm{P}$ & $\leq 0.001$ & $\leq 0.001$ & $\leq 0.001$ & $\leq 0.001$ & $=0.2$ & $\leq 0.001$ & $\leq 0.001$ & & & & \\
\hline & $\begin{array}{l}\text { LSD at } \\
\mathrm{P} \leq 0.05\end{array}$ & 8.65 & 0.62 & 0.5 & 7.7 & NS & 7 & 8.7 & & & & \\
\hline \multirow{9}{*}{$\begin{array}{l}\text { Emergence } \\
(\%)(\text { Mean } \\
\pm \mathrm{SE})\end{array}$} & 16 & $68.6 \pm 0.2$ & $77.6 \pm 2.2$ & $80.2 \pm 1.5$ & $75.0 \pm 3.23$ & $82.2 \pm 2$ & $84.4 \pm 2$ & $9.6 \pm 2$ & 6,28 & 33.3 & $\leq 0.001$ & 7 \\
\hline & 21 & $82.0 \pm 1$ & $65.6 \pm 2.2$ & $77.6 \pm 2.6$ & $81.2 \pm 4.14$ & $87.6 \pm 2$ & $81.0 \pm 1.5$ & $93.4 \pm 2.2$ & 6,28 & 42.7 & $\leq 0.001$ & 5.6 \\
\hline & 26 & $92.6 \pm 1$ & $94.2 \pm 1.6$ & $92.0 \pm 3.4$ & $94.6 \pm 1.2$ & $79.0 \pm 2.3$ & $89.8 \pm 2.5$ & $88.4 \pm 2.8$ & 6,28 & 57.8 & $\leq 0.001$ & 6.4 \\
\hline & 31 & \begin{tabular}{|l|l|}
$79.8 \pm 1.3$ \\
\end{tabular} & $82.4 \pm 1.4$ & \begin{tabular}{|l|}
$54.0 \pm 2.4$ \\
\end{tabular} & $70.6 \pm 1.6$ & \begin{tabular}{|l|}
$71.6 \pm 1.5$ \\
\end{tabular} & \begin{tabular}{|l|}
$77.4 \pm 1.5$ \\
\end{tabular} & $75.2 \pm 2$ & 6,28 & 32.8 & $\leq 0.001$ & 6.6 \\
\hline & 36 & $64.8 \pm 2.3$ & $71.2 \pm 3.7$ & $44.4 \pm 1.6$ & $59.6 \pm 2.8$ & $59.4 \pm 3.7$ & $52.8 \pm 3.2$ & $58.8 \pm 3.2$ & 6,28 & 9.3 & $\leq 0.001$ & 5.9 \\
\hline & $\mathrm{df}$ & 4,20 & 4,20 & 4,20 & 4,20 & 4,20 & 4,20 & 4,20 & & & & \\
\hline & $\mathrm{F}$ & 42.88 & 25.72 & 67.18 & 20.72 & 21.58 & 32.5 & 29.3 & & & & \\
\hline & $\mathrm{P}$ & $\leq 0.001$ & $\leq 0.001$ & $\leq 0.001$ & $\leq 0.001$ & $\leq 0.001$ & $\leq 0.001$ & $=0.4$ & & & & \\
\hline & $\begin{array}{l}\text { LSD at } \\
\mathrm{P} \leq 0.05\end{array}$ & 5 & 7 & 7.1 & 8.4 & 6.9 & 7.4 & 5.6 & & & & \\
\hline
\end{tabular}

T. jap- T. japonicum, T. ach- T. achaeae, T. cor- T. cordubensis, T. ch lab - T. chilonis Laboratory strain, T. ch Nigiris- T. chilonis Nilgiris strain, T. ch $15^{\circ} \mathrm{C}$ - T. chilonis maintained at $15^{\circ} \mathrm{C}$, T. ch Kodai- T. chilonis Kodaikanal strain \# Analysis based on square root transformed values 
except $31^{\circ} \mathrm{C}$ at which $T$. achaeae recorded significantly higher MDF (Table 2).

\section{Mean life time fecundity (MLF)}

MLF was influenced by temperature for all the spp./ strains except $T$. chilonis Nilgiris. The highest MLF could be recorded at 21 and $26^{\circ} \mathrm{C}$ for T. japonicum, $31^{\circ} \mathrm{C}$ for $T$. achaeae, $26^{\circ} \mathrm{C}$ for $T$. chilonis lab population, 16 to $31^{\circ} \mathrm{C}$ for T. chilonis Kodaikanal and 21 and $26^{\circ} \mathrm{C}$ for T. chilonis $15^{\circ} \mathrm{C}$ strain. T. cordubensis could record equally good MLF from 16 to $26^{\circ} \mathrm{C}$. When compared across the spp./strains $T$. chilonis Nilgiris predominantly recorded highest MLF at the five test temperatures (Table 2).

\section{Percent emergence $(\% \mathrm{E})$}

Peak adult emergence was recorded at $26^{\circ} \mathrm{C}$ for all the spp./strains except $T$. chilonis Nilgiris where highest emergence was recorded at $26^{\circ} \mathrm{C}$ and $16^{\circ} \mathrm{C}$, both being statistically on par. When data was on compared across the spp./ strains at different temperature, at $16^{\circ} \mathrm{C}$ T. chilonis $15^{\circ} \mathrm{C}$, T. chilonis Nilgiris and T. cordubensis recorded highest emergence and at $21^{\circ} \mathrm{C}$ T. chilonis Nilgiris and T. japonicum recorded peak emergence rate. At $26^{\circ} \mathrm{C}$ except $T$. chilonis Nilgiris and T. chilonis Kodaikanal all the other spp./ strains showed significantly high percent adult emergence. At 31 and $36^{\circ} \mathrm{C}$ T. achaeae and T. japonicum recorded highest adult emergence (Table 2).

The current study indicates a clear inverse relationship between developmental duration and temperatures. This is probably because of the increasing metabolic activity in insects at higher temperatures. Though the trend of increasing developmental rate with rise in temperature was similar among the species and strains of Trichogramma, each spp./ strain recorded significantly different response with respect to biological parameters indicating that biological performances depend not only on existing temperature but also on the adaptation of species and strains to that temperature (Pratissoli and Parra, 2000; Zago et al., 2006).
For mass production and field release of a bio-agent, shorter developmental duration is considered desirable. In our present study, significantly shorter developmental duration coupled with good parasitizing ability (ranging between 44 to $65 \%$ )recorded at higher temperatures for all the test spp./strains (except T. chilonis lab and T. cordubensis) indicates that these species could be chosen as ideal candidates for field evaluations in high temperature zones. The inferior performance of T. chilonis lab strain and T. cordubensis with respect to longer developmental durations and low parasitism rates could be due to continuous lab rearing under controlled conditions in the case of the former and the exotic origin of the latter species.

The temperature threshold study was aimed to identify the temperature range within which normal development occurs and the species/strain can remain active. The lower threshold temperature (LT) for the different species/strains ranged from 9.3 to $12^{\circ} \mathrm{C}$. The variation in LT in different species could be due to the different thermal requirements of the host as well as the strainal variations (Pratissoli, 1879).Trichogramma japonicum, T. chilonis lab, T. chilonis Nilgiris and T. chilonis Kodaikanal had similar thermal requirement of 166.66 heat units while T. chilonis $15^{\circ} \mathrm{C}$ required 142.85 heat units to complete development above the threshold temperature. However, the lower threshold temperature ranged between 10 to $12^{\circ} \mathrm{C}$ and upper threshold temperature ranged from 37.5 to 39.1 for all these indigenous species. This probably indicates that the above spp./strains share the same genetic make-up except the $15^{\circ} \mathrm{C}$ strain which showed a clear variation due to its long term acclimatization to a lower temperature. The higher thermal requirement, upper threshold and lower threshold temperature of the exotic $T$. cordubensis indicates that in spite of continuous lab rearing, this species remains to be the least heat sensitive one. The geographical origin of this species could have a bearing on its response to temperature.

Table 3. Lower temperature threshold (LT), upper threshold (UT) values and thermal constants (K) of different spp./strains of Trichogramma

\begin{tabular}{|l|l|l|l|l|l|l|}
\hline Spp./Strains & Equation & $\mathrm{R}^{2}$ & $\mathrm{P}$ & $\mathrm{LT}$ & $\mathrm{UT}$ & $\mathrm{K}$ \\
\hline T. japonicum & $\mathrm{y}=0.006 \mathrm{x}-0.062$ & 0.99 & $\leq 0.0001$ & 10.3 & 38.1 & 166.66 \\
\hline T. achaeae & $\mathrm{y}=0.005 \mathrm{x}-0.053$ & 0.99 & $\leq 0.0001$ & 10.6 & 39.2 & 200.00 \\
\hline T. cordubensis & $\mathrm{y}=0.003 \mathrm{x}-0.028$ & 0.98 & $\leq 0.0001$ & 09.3 & 46.4 & 333.00 \\
\hline T. chilonis lab & $\mathrm{y}=0.006 \mathrm{x}-0.068$ & 0.97 & $\leq 0.0001$ & 11.3 & 39.1 & 166.66 \\
\hline T. chilonis Nilgiris & $\mathrm{y}=0.006 \mathrm{x}-0.072$ & 0.95 & $\leq 0.0001$ & 12.0 & 37.6 & 166.66 \\
\hline T. chilonis $15^{\circ} C$ & $\mathrm{y}=0.007 \mathrm{x}-0.082$ & 0.98 & $\leq 0.0001$ & 11.7 & 35.5 & 142.85 \\
\hline T. chilonis Kodai & $\mathrm{y}=0.006 \mathrm{x}-0.061$ & 0.94 & $\leq 0.0001$ & 10.0 & 37.9 & 166.66 \\
\hline
\end{tabular}


Longevity of Trichogramma spp. was observed to be clearly influenced by temperature. In general, higher longevity was recorded at lower temperature of $16^{\circ} \mathrm{C}$, with $T$. cordubensis being significantly superior to the rest at this temperature. However, T. chilonis Nilgiris showed a clear preference for $21^{\circ} \mathrm{C}$. At 21 and $26^{\circ} \mathrm{C}$ T. chilonis Nilgiris and at 31 and $36^{\circ} \mathrm{C} T$. achaeae emerged as the superior strains with respect to longevity. This clearly indicates the low temperature preference and cold hardy nature of $T$. cordubensis and high temperature preference of $T$. achaeae. Temperature provided during development is known to affect the biological parameters of Trichogramma adults (Prasad et al., 2002). This was true in the case of T. chilonis $15^{\circ} \mathrm{C}$, which was acclimatized to low temperature and it recorded higher percent emergence and longevity at $16^{\circ} \mathrm{C}$. Emergence rates of $T$. japonicum, $T$. chilonis lab, T. achaeae and $T$. cordubensis were best at $26^{\circ} \mathrm{C}$, which is probably because the populations used for our study were reared for more than 200 generations at a lab temperature of $26 \pm 1^{\circ} \mathrm{C}$.

Earlier studies have estimated the impact of temperature during development on fecundity of Trichogramma spp. Though the parasitism rate peaked at $20^{\circ} \mathrm{C}$ for some trichogrammatids, in most cases the highest number of host parasitized within a certain period of time was recorded at $25^{\circ} \mathrm{C}$ (Harrison et al., 1985; Pavlik, 1992; Reznik and Vaghina, 2006). Our results coincide with the above studies with respect to fecundity of $T$. chilonis as all the strains of this species recorded higher fecundity at $26^{\circ}$ C.T. chilonis Nilgiris recorded highest parasitism rates and fecundity in all the temperatures probably because of the fact that this strain had gone through few generations in the lab and hence biological attributes had not deteriorated. Trichogramma achaeae recorded highest parasitism and fecundity at $31^{\circ} \mathrm{C}$ which reflect its relative preference for higher temperatures. Similar observations were made in the case of Trichogramma nubilate Ertle \& Davis, where maximum parasitism rate was recorded between 25 and $30^{\circ} \mathrm{C}$ (Russo and Voegele, 1982). In the current study all the T. chilonis strains recorded higher fecundity at $26^{\circ} \mathrm{C}$.

Based on the results of our current study, we could interpret that in general, considering parasitism and fecundity the suitable rearing temperature is $26^{\circ} \mathrm{C}$ for all the spp./ strains of Trichogramma. Amongst the different strains of $T$. chilonis, the Nilgiris strain proved to be superior to all the other strains and species with reference to its high fecundity and parasitism. This strain also showed a clear adaptation to different temperatures. This strain can thus be identified for mass rearing and field releases. T. chilonis lab strain and T. cordubensis could not parasitize well at con- stant higher temperatures. However, in the field situation the parasitoids would be exposed to varying temperatures with periodic respites from extreme hot or cold temperatures which would enhance the chances of survival of these spp./strains. The narrow temperature preferences of the $\mathrm{spp}$./strains which were continuously lab reared for several generations and the plasticity of the recently field collected strains emerged through this study. It is thus important to identify the maximum number of generations each Trichogramma spp./strains can go through in the laboratory so that rejuvenation of the culture can be initiated at the right stage to prevent deterioration of its biological parameters.

It would be worth investigating if rejuvenation of the lab population of each species with the wild culture of the same species could improve its adaptability to a wider range of temperatures. Besides, we also suggest that the indigenous T. chilonis Nilgiris strain which holds the capacity to perform well at a wider range of temperatures is an ideal candidate for future studies on diapause induction (leading to long term storage). This would definitely address the current problem of low shelf-life of Indian Trichogrammatids.

\section{ACKNOWLEDGMENTS}

The funding provided by the Department of Biotechnology, Government of India for this research project (code: BT/PR3339/AGR/5/558/2011) is gratefully acknowledged. We are grateful to Dr. Y. Lalitha for the cultures of C. cephalonica and T. chilonis $15^{\circ} \mathrm{C}$ strains.

\section{REFERENCES}

Arnold CY. 1959. The development and significance of the base temperature in a linear heat unit system. Proc Am Soc Hort Sci. 74: 430-445.

Briere FJ, Pracos P, Roux AL, Pierre JS. 1999. A novel rate model of temperature-dependent development for arthropods. Environ Entomol. 28(1): 22-29. Crossref

Chailleux A, Biondi A, Han P, Tabone E, Desneux N. 2013. Suitability of the host-plant system Tuta absoluta tomato for Trichogramma parasitoids and insights for biological control. J Econ Entomol. 106: 2310-2321. Crossref PMid:24498728

Corrigan JE, Laing JE. 1994. Effects of the rearing host species and the host species attacked on performance by Trichogramma minutum Riley (Hymenoptera: Trichogrammatidae). Biol Control 23: 755-760. Crossref 
El Arnaouty SA, Pizzol J, Galal HH, Kortam MN, Afifi AI, Beyssat V, Desneux N, Biondi A, HeikalI. 2014. Assessment of two Trichogramma species for the control of Tuta absoluta in North African tomato greenhouses. Afr Entomol. 22: 801-809. Crossref

Foerster RM, Foerster AL. 2009. Effect of temperature on the immature development and emergence of five species of Trichogramma. BioControl 54: 445-450. Crossref

Garcia P, Oliveira L, Tavares J. Comparative biology of three Trichogramma spp. populations captured in Azores. 1995b. Bol Mus Munic Funchal 4: 311-318.

Garcia P. 1995. Trichogramma cordubensis Vargas \& Cabello (Hym.,Trichogrammatidae) nailha de $S$. Miguel (Açores): Aspectos de Sistematica e Ecologia. Dissertation, Universidade dos Açores, Acores. p. $1-114$.

Harrison WW, King EG, Ouzts JD. 1985. Development of Trichogramma exiguum and Trichogramma pretiosum at five temperature regimes. Environ Entomol. 14: 118-121. Crossref

Lalitha Y, Ballal CR. 2015. Influence of seasons and inoculum dosages on the production efficiency of Corcyra cephalonica Stainton. J Biol Control 29(1): 25-30. Crossref

Lingappa S, Hegde S. 2001. Exploitation of bio-control potential in the management of insect pests of pulse crops. Biocontrol Pot Exploitation Sustainable Agric. 2: 321-344.

Mani M, Krishnamoorthy A, Gopalkrishnan C, Rabindra R. 2001. Augmentative biocontrol within vegetable IPMIndian scenario. In: Singh SP, Murphy ST, Ballal CR (Eds.) Augmentative Biocontrol. CABI Bioscience, UK and Project directorate of biological control (ICAR), Bangalore, India. p. 119-140.

Morris RF, WC Fulton. 1970. Models for the development and survival of Hyphantriacuneain relation to temperature and humidity. Mem Entomol Soc Can. 70: 1-60. Crossref

Nagarkatti S, Nagaraja H. 1977. Biosystematics of Tricho gramma and Trichogrammatoidea species. Annu Rev Entomol. 22:157-76. Crossref

Pak GA, Oatman ER. 1982. Comparative life table, behavior and competition studies of Trichogramma brevicapil- lum and Trichogramma pretiosum. Ent Exp and Appl. 31: 68-79. Crossref

Pavlik J. 1992. The effect of temperature on parasitization activity in Trichogramma spp. (Hymenoptera, Trichogrammatidae). Zool Jb Physiol. 96: 417-425.

Pizzol J, Pintureau B, Khonaldia O, Densneux N. 2010. Temperature dependent differences in biological traits between two strains of Trichogramma cacoeciae (Hymenoptera: Trichogrammatidae). J Pest Sci. 83: 447-452. Crossref

Prasad RP, Roitberg BD, Henderson DE. 2002. The effect of rearing temperature on parasitism by Trichogramma sibericum Sorokina at ambient temperatures. Biol Control 25: 110-115. Crossref

Pratissoli D, Parra JRP. 2000. Fertility life table of Trichogramma pretiosum (Hym., Trichogrammatidae) in eggs of Tuta absoluta and Phthorimaea operculella (Lep., Gelechiidae) at different temperatures. J Appl Entomol. 124: 339-342. Crossref

Pratissoli D. Bioecologia de Trichogramma pretiosum Riley, 1879, nastracasscrobipalodes absoluta (Mayrick, 1917) e phtrorimaeaoperculella (Zeller, 1879), emtomateirotese de dontorado, Escola superior de agricultura "Luizequeiroz", piravcicaba-sp, 1995.

Ratte HT. 1985. Temperature and insect development. In: Hoffmann KH. (Ed.). Environmental physiology and biochemistry of insects. Springer, Berlin. p. 33-66.

Reznik SYA, Vaghina NP. 2006. Temperature effects on induction of parasitization by females of Trichogramma principium (Hymenoptera, Trichogrammatidae). Entomol Rev. 86: 133-138. Crossref

Russo J, Voegele J. 1982. Influence de la temperature surquatreespeces de Trichogrammes (Hym. Trichogrammatidae) parasite de la pyrale du mas, Ostrinia nubilalis Hubn. (Lep. Pyralidae). II Reproduction etsurvie Agronomie. 2: 517-524. Crossref

Singh SP, Murphy ST, Ballal CR. Augmentative biocontrol in India. In: Proceedings of the ICAR-CABI workshop June 29-July 1, 2000; 2001. p. 1-20.

Urra F, Apablaza J. 2005. Threshold temperature and thermal constant for the development of Copitarsiadecolora (Lepidoptera: Noctuidae). CienInvAgr. 3216-23. 
Ghosh et al.

Zago BH, Pratissoli D, Barras R, Gondin JR. 2006. Biologiaeexigenciastermicas de Trichogramma pratissolii Querino \& Zucchi (Hymenoptera: Trichogrammatidae) emhespedeiros alternatives. Neotrop Entomol. 35: 377381. Crossref PMid:18575699
Zehnder G, Gurr MG, Kuhne S, Wade RM, Wratten DS, Wyss E. 2007. Arthropod pest management in organic crops. Annu Rev of Entomol. 52: 57-80. Crossref PMid: 16846384 